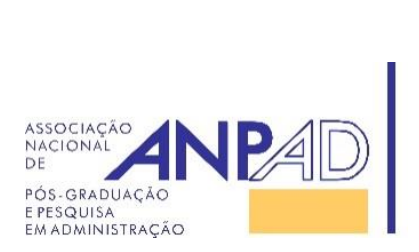
Disponível em
http://www.anpad.org.br/rac
RAC, Rio de Janeiro, v. 21, n. 5, art. 2,
pp. 627-647, Setembro/Outubro, 2017
http://dx.doi.org/10.1590/1982-7849rac2017160163

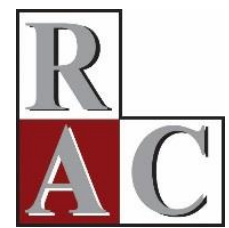

(c)) EY

\title{
Disputas Discursivas sobre Corrupção no Brasil: Uma Análise Discursivo-Crítica no Twitter
}

Discursive Disputes on Corruption in Brazil: A Discursive-Critical Analysis on Twitter

\author{
André Luiz de Paiva ${ }^{1}$ \\ André Spuri Garcia ${ }^{1}$ \\ Valderí de Castro Alcântara ${ }^{1}$ \\ Universidade Federal de Lavras ${ }^{1}$
}

Artigo recebido em 28.06.2016. Última versão recebida em 06.03.2017. Aprovado em 10.03.2017. Publicado online em 25.05.2017. 


\title{
Resumo
}

Objetivamos analisar quais e como as representações dos discursos sobre corrupção no Brasil, publicizados no Twitter, são mobilizadas em disputas discursivas. Para tanto, utilizamos a análise crítica do discurso, com destaque para o significado representacional deste, e o conceito de disputas discursivas operacionalizadas em três instâncias. Metodologicamente, delimitamos dois escândalos de corrupção de grande repercussão nacional e buscamos enunciados publicados no Twitter, durante os meses de agosto de 2014 e fevereiro de 2016. Assim, coletamos tweets das revistas Veja e CartaCapital, e de usuários/leitores que responderam a estes enunciados. Percebemos que o Twitter configura-se atualmente, no Brasil, como um espaço de disputas sobre os significados da corrupção marcados por dinâmicas de naturalizações, seletividade dos media, expurgo do outro, inclusão/exclusão, nomeação e estratégias de racionalização e avaliação moral. Observamos, também, que os discursos sobre a corrupção se intensificaram recentemente, sobretudo devido ao clima político-partidário nacional. Finalmente, os resultados apontam que a construção da corrupção é o resultado de processos de produção de sentidos inseridos em um contexto de campos sociais e políticos, com o papel marcante da mídia na construção de escândalos.

Palavras-chave: corrupção; Twitter; disputas discursivas; mídia.

\begin{abstract}
We aimed to analyze which and how representations of discourses about corruption in Brazil, publicized on Twitter, are mobilized in discursive struggles. Therefore, we use critical discourse analysis, highlighting the representational meaning of discourses and the concept of discursive struggles as operationalized in three instances. Methodologically, we delimited two corruption scandals with national repercussions and searched for statements published on Twitter during the months from August 2014 to February 2016. Thus, we collected tweets from magazines Veja and CartaCapital and users/readers who responded to these statements. We realize that Twitter currently set up in Brazil as a space for disputing the meanings of corruption marked by dynamics of naturalization, media selectivity, purging of the other, inclusion/exclusion, appointment and moral evaluation and rationalization strategies. We also note that the discourse on corruption has recently intensified, mainly due to the national party-political climate. Finally, the results indicate that the construction of corruption is the result of sense making processes inserted in social and political fields with remarkable role of the media in the construction of scandals.
\end{abstract}

Key words: corruption; Twitter; discursive dispute; media. 


\section{Introdução}

Pesquisas recentes têm demonstrado como as redes sociais contribuem para a pluralização e a distribuição de debates sobre diversos temas polêmicos (Jackson \& Valentine, 2014). Com destaque nos anos de 2015 e 2016, a questão da corrupção no Brasil se tornou elemento presente na mass media, nas redes sociais e nas conversas cotidianas. Uma análise inicial revela a existência de diversos debates sobre a temática no Twitter. Esses temas emergem, sobretudo, diante do clima de instabilidade política observado em 2015 e 2016, envolvendo escândalos de corrupção, posições divergentes sobre o processo de impeachment, grandes manifestações e outros conflitos diversos, e a polarização partidária - acirrada durante e após a última eleição presidencial (em 2014) - que afeta os discursos sobre a corrupção e seus significados.

Neste artigo, entendemos que tais relações podem ser estudadas tomando como apoio a abordagem teórico-metodológica da análise de discurso crítica (Fairclough, 2001, 2003) e o conceito de disputas discursivas (Barros, 2014; Hardy \& Phillips, 1999). Esses embasamentos oferecem elementos consistentes para realizar estudos sobre corrupção no Brasil a partir do entendimento: (a) do discurso como prática social; (b) da relação dialética entre discurso e sociedade; (c) dos efeitos ideológicos do discurso; (d) das disputas discursivas envolvendo temas específicos; e (e) dos meios de comunicação como fundamentais para a análise de lutas discursivas (Barros, 2014; Fairclough, 2003; Hardy \& Phillips, 1999).

Diversos pesquisadores vêm mostrando o potencial da análise de discurso crítica para o estudo de textos publicados em redes sociais (Chiluwa, 2012; Chiluwa \& Ifukor, 2015; Mautner, 2005) e a análise de disputas discursivas desenvolvidas nos meios de comunicação tradicionais, nas redes sociais, nos blogs, entre outros meios (Barros, 2014). Nisso, consideramos também como caminho de pesquisa a indicação de Breit (2010) no que tange ao estudo das representações da corrupção na mídia e como a corrupção é também socialmente construída, sobretudo ao se considerar uma perspectiva crítica. Além disso, partimos do entendimento da corrupção como um conceito relacional e constituído por processos discursivos e mediatizados (Breit, 2010). Argumentamos que os significados desse fenômeno são influenciados pelas lutas políticas em curso e por polarizações político-partidárias (Breit, 2010) pesquisa recente demonstrou tal elemento no contexto brasileiro (P. F. Ribeiro, Vizoná, \& Cassota, 2016).

Ademais, para a construção desta pesquisa, procuramos destacar os seguintes elementos: estudar como a corrupção é social e discursivamente construída (Breit, 2011); observar como a mídia e as redes sociais influenciam na construção das representações sobre a corrupção (Breit, 2010; Damgaard, 2015); constatar que o entendimento da corrupção como algo natural ao brasileiro não amplia nosso potencial analítico (Avritzer, 2016; Avritzer \& Filgueiras, 2011; Filgueiras, 2009); e asseverar que o conceito de disputa discursiva nos ajuda a analisar a formação de debates com posições antagônicas evidentes (Barros, 2014; Harley \& Hardy, 2004). Além disso, é marcante que existe uma lacuna de pesquisas nos Estudos Organizacionais sobre o tema corrupção (em uma perspectiva ampla e não somente na perspectiva da corrupção organizacional). Recentemente, esse tema foi central no IX Encontro de Estudos Organizacionais da ANPAD (EnEO), realizado em 2016. Outros meios também procuraram explorar discussões sobre corrupção como, por exemplo, a edição especial de 2015, Critiquing Corruption: A Turn to Theory do periódico ephemera: theory \& politics in organisation, e também o European Group for Organizational Studies (EGOS). Portanto, este artigo é, inclusive, mais um passo de uma agenda de pesquisa sobre corrupção nos Estudos Organizacionais.

Frente ao exposto, visamos responder ao seguinte questionamento: Quais são as representações dos discursos sobre corrupção no Brasil publicizados no Twitter e como elas são mobilizadas em disputas discursivas? Diante disso, nosso objetivo é analisar quais e como as representações dos discursos sobre corrupção no Brasil publicizados no Twitter são mobilizadas em disputas discursivas. Para tanto, definimos duas operações judiciais relacionadas a escândalos de corrupção de grande repercussão no país, a saber: a operação Lava-Jato, que investiga crimes de lavagem de dinheiro, 
propinas, desvios de recursos públicos, dentre outras práticas de corrupção; e a operação Zelotes, focada em práticas de corrupção junto ao Conselho Administrativo de Recursos Fiscais (Carf).

A partir desses casos, procuramos por enunciados publicados no Twitter por dois veículos da grande mídia - Revista Veja e Revista CartaCapital - bem como enunciados que representassem respostas de usuários/leitores desses textos. O período de composição do corpus de análise foi entre agosto de 2014, coincidindo com o período das eleições presidenciais de 2014, e fevereiro de 2016, já marcado pelo processo de impeachment da ex-presidente Dilma Rousseff.

Além dessa introdução, apresentamos um breve debate sobre corrupção, tendo o Twitter como espaço de discussão, disputas discursivas e o conceito de discurso. Em seguida, a metodologia e os resultados, que destacam como a corrupção vem sendo debatida e publicizada no contexto atual brasileiro em três momentos de disputas discursivas. Por fim, as considerações finais.

\section{Direcionamentos Teóricos do Fenômeno da Corrupção}

Em um conceito formulado por Rose-Ackerman (2001), a corrupção refere-se a um comportamento racional e autointeressado de pessoas utilizando seu poder de discrição para direcionar alocações de recursos para si mesmas ou outros atores sociais que oferecem recompensas em favor a esse ato. No entanto, Breit, Lennerfors e Olaison (2015) argumentam que tal teorização deve ser repensada a partir de uma perspectiva crítica para os estudos sobre corrupção - uma perspectiva que busque superar a simplificação do conceito, desvelar as ideologias existentes nas práticas tidas como corruptas e explorar fenômenos tais como os discursos de corrupção que são representados pela mídia e outros atores sociais.

Além disso, conforme Gupta (1995), assumindo que a corrupção esteja relacionada à violação de normas e padrões de conduta, e que tais normas são socialmente construídas e contextualmente localizadas, são comuns as divergências e os conflitos de sentidos e significados quanto a uma determinada prática ser corrupta ou não. Logo, a corrupção não pode ser entendida apenas no conceito legal. Adiante, segundo Breit (2011) e Abramo (2005), a corrupção é um fenômeno complexo de se pesquisar, afinal, sua percepção está atrelada à opinião de um indivíduo ou coletividade e sofre com os efeitos de inclinações ideológicas.

Segundo Gupta (1995), o discurso sobre a corrupção é construído por meio de práticas culturais pelas quais o Estado ou as outras organizações são simbolicamente representados pelos indivíduos que as constituem, a partir de discussões intermediadas pela mídia. Nisso, a corrupção frequentemente recebe grande atenção da mídia, embora seja abordada de forma que o essencial não é a veracidade dos casos - constituindo, também, a mediatização do fenômeno (Strömbäck \& Esser, 2014). Nessas situações, o debate público envolvendo discursos de defesa ou condenação das práticas tidas como corruptas fazem com o que o fenômeno seja tratado como um evento midiático que promove influência na realidade política (Breit, 2011).

Para Damgaard (2015), a corrupção pode ser entendida como um evento midiático com consequências sociológicas e eficácia política. É justamente a existência mediatizada da corrupção que produz diferentes efeitos na organização política da sociedade. Assim, a representação da corrupção depende da organização política e dos sentidos atribuídos às transgressões tidas como corruptas ou não. Nisso, a construção social da corrupção é um fenômeno em disputa, ambíguo e multifacetado, de modo que essa concepção proporciona diferentes implicações paras as relações sociais (Breit, 2011). Isso envolve, dentre outros elementos, o aumento nos conflitos entre diferentes pontos de vista políticos quanto à questão da corrupção (Breit, 2011; Damgaard, 2015).

No caso do Brasil, é importante considerar, junto a Filgueiras (2009), que a corrupção não é um tipo de comportamento natural, específico do brasileiro ou de certo grupo (funcionários públicos, por exemplo). Corroborando com isso, Avritzer e Filgueiras $(2011$, p. 8) afirmam que a "naturalização da 
prática da corrupção no Brasil promove um tipo de abordagem [que apresenta] problemas a seu efetivo controle democrático", pois pode levar à ideia de que seria preciso esperar rupturas culturais e institucionais para modificar o status da corrupção no país. Avritzer (2016, p. 85) coloca também que "vale a pena prestar um pouco mais de atenção para [as] ambiguidades na cultura política brasileira em relação à corrupção". A partir disso, a corrupção é, na verdade, um fenômeno global, mesmo com variados níveis de práticas, representações e percepções (Abramo, 2005; Avritzer, 2016).

\section{Twitter como esfera de discussão}

O Twitter é uma rede social que tem diminuído as barreiras para a participação e o debate devido à natureza pública da comunicação desenvolvida em seu espaço. Essa rede permite que pessoas se comuniquem diretamente por meio de textos (tweets) e menções a outros usuários (mentions), bem como compartilhem (por meio de retweets) e se engajem em determinados tópicos ou assuntos (utilizando hashtags) (Ausserhofer \& Maireder, 2013).

Para Jackson e Valentine (2014), ao se considerar os espaços de discussão online, os sujeitos são ao mesmo tempo consumidores e produtores, transformando esses fóruns em importantes ferramentas do discurso público. O Twitter possibilita discussões envolvendo aspectos políticos, sociais e emocionais que promovem influência nas práticas cotidianas. Entretanto, pode ser um espaço no qual a distância social entre usuários promove disfunções nos diálogos (abusos, injúrias, etc.) e outras formas expressivas não democráticas - como os discursos de ódio (Jackson \& Valentine, 2014).

No que tange aos aspectos positivos, a publicização de vários debates e temas se torna o elemento democrático mais importante do Twitter (Ausserhofer \& Maireder, 2013). Referente a isso, a rede é lembrada pela sua participação em casos de mobilizações recentes, como destacado por Maireder e Schlögl (2014).

Outra questão relevante para a compreensão da rede enquanto esfera de discussão refere-se ao uso de bots sociais (socialbot). O socialbot é um software programado para agir como usuários reais e que controla uma conta em uma determinada rede social (Boshmaf, Muslukhov, Beznosov, \& Ripeanu, 2012). Os socialbots são utilizados de forma estratégica como, por exemplo, para propagar notícias e informações, amplificar campanhas publicitárias e divulgar pesquisas científicas (Haustein et al., 2016). Por outro lado, podem ser usados para espalhar vírus, discursos de ódio, obter informações pessoais de outros usuários (Haustein et al., 2016) e manipular a opinião pública (Woolley, 2016).

\section{Disputas discursivas no contexto das redes sociais}

Os textos podem ser entendidos como práticas discursivas que estão localizadas em um contexto, construindo sentidos que podem ser mobilizados em disputas discursivas (Barros, 2014). Nessas disputas, os atores sociais utilizam os "textos como armas" (Barros, 2014, p. 1212) para moldar e transformar a realidade social (Barros, 2014; Hardy \& Phillips, 1999).

Segundo Barros (2014), as disputas discursivas se formam quando diferentes atores constroem estratégias discursivas que visam criticar ou defender uma posição hegemônica, bem como legitimar/deslegitimar grupos ou ações. Conforme Gleiss (2015), em alguns casos é fácil identificar as disputas discursivas em curso, mas em outros, não, demandando uma análise mais complexa e que considere o contexto em que as disputas estão inseridas.

As redes sociais na internet emergiram como possibilidades para amplas disputas discursivas. Nesses espaços, as disputas têm assumido diferentes características, sobretudo pelo fato de que os discursos produzidos não são controlados apenas por produtores de conteúdo tradicionais, mas dividem espaço com usuários que (re)produzem uma diversidade de textos, muitas vezes procurando legitimar narrativas contra-hegemônicas (Barros, 2014).

Além do apresentado, nas disputas discursivas, a mídia (mass media) pode interferir nos processos de legitimação (Breit, 2011), criando, transformando, produzindo e reproduzindo discursos de amplo 
alcance. Especificamente, Breit (2010) coloca que, nas lutas de poder entre diferentes interpretações sobre a corrupção, podemos compreender como elas são construídas e reconstruídas socialmente. Ainda sobre a mídia, é importante a questão da midiatização (Strömbäck \& Esser, 2014) de determinados temas, como a corrupção (Cobb \& Taylor, 2015).

\section{Perspectivas de Discurso na Análise Crítica do Discurso (ADC) de Fairclough}

O termo Critical Discourse Analysis foi usado por Norman Fairclough (1985), autor que viria a se tornar a principal referência dessa perspectiva teórico-metodológica (Resende \& Ramalho, 2006). Para Fairclough (2001), sua abordagem visa englobar perspectivas linguísticas e do pensamento social em prol de um amplo arcabouço teórico e metodológico de pesquisa. Por isso, a ADC:

é muito mais uma teoria que um método, ou melhor, uma perspectiva teórica sobre a língua e, de uma maneira mais geral, sobre a semiose (que inclui a linguagem visual, linguagem corporal, e assim por diante) como um elemento ou momento do processo social material (Williams, 1977), que dá margem a análises linguísticas ou semióticas inseridas em reflexões mais amplas sobre o processo social (Fairclough, 2012, pp. 307-308).

Nessa direção, para Fairclough (2001, p. 91), "o discurso [é] um modo de ação, uma forma em que as pessoas podem agir sobre o mundo e especialmente sobre os outros, como também um modo de representação". Para o autor, isso implica no entendimento de que os discursos tanto são moldados quanto transformam as estruturas sociais. Além disso, esclarece: "ao usar o termo 'discurso', proponho considerar o uso da linguagem como forma de prática social e não como atividade puramente individual ou reflexo de variáveis situacionais" (Fairclough, 2001, p. 90). Isso tem as seguintes implicações na visão dele:

Primeiro, implica ser o discurso um modo de ação, uma forma em que as pessoas podem agir sobre o mundo e especialmente sobre os outros, como também um modo de representação.... Segundo, implica uma relação dialética entre o discurso e a estrutura social, existindo mais geralmente tal relação entre a prática social e a estrutura social: a última é tanto uma condição como efeito da primeira. Por outro lado, o discurso é moldado e restringido pela estrutura social. (Fairclough, 2001, p. 91).

Fairclough (2001) coloca ainda que o discurso mantém e transforma relações de poder e significados do mundo e, portanto, podem ser investidos de ideologias. Por sua vez, em Fairclough (2003) existe um movimento da noção da linguagem como prática social para a linguagem como relacionada a outras práticas sociais. Nisso, para o autor, a ADC "é a análise das relações dialéticas entre semioses (inclusive a língua) e outros elementos das práticas sociais" (Fairclough, 2012, p. 309). Nesse processo, o discurso é um elemento das práticas sociais que se relaciona dialeticamente com outras práticas (Chouliaraki \& Fairclough, 2010).

Adiante, Fairclough (2003) apresenta a existência analítica de três significados do discurso: o acional (o texto como modo de interação), o representacional (representações nos textos) e o identificacional (construções e negociações de identidades no discurso). Portanto, os discursos são modos de interação, representação e construção de identidades (Fairclough, 2003). Apesar da separação entre as categorias ser apenas analítica, este artigo possui ênfase no significado representacional do discurso. Abordaremos categorias do significado representacional do discurso a seguir. 


\section{Perspectiva Teórico-Metodológica}

Conforme mencionado, a análise de discurso crítica é uma abordagem teórico-metodológica (Fairclough, 2003; Resende \& Ramalho, 2006) que se tornou relevante para os estudos organizacionais (Chouliaraki \& Fairclough, 2010; Fairclough, 2005). Nessa seção, apresentamos especificamente os elementos do significado representacional que guiaram nossas análises e os processos de coleta e organização do corpus de análise.

\section{O significado representacional do discurso}

O significado representacional está relacionado com a representação dos processos e dos atores sociais no discurso (Fairclough, 2003). Para Fairclough (2003), as representações estão relacionadas com posições sociais, econômicas, dentre outras e, diante disso, um mesmo episódio pode produzir vários discursos distintos. Nesse significado, a análise é operacionalizada pelas categorias representação dos atores sociais, interdiscursividade e significado das palavras.

Sobre a representação dos atores sociais, Fairclough (2003) considera que os atores são representados nos discursos. A partir de Theo van Leeuwen, destaca também as diversas representações dos atores sociais que podem ser analisadas por meio das relações de inclusão/exclusão, voz ativa ou passiva, específico ou genérico, dentre outros. Por meio disso, a análise das representações dos atores "pode ser útil no desvelamento de ideologias em textos e interações" (Resende \& Ramalho, 2006, p. 72). A questão da representação dos atores sociais foi usada em estudos como o de Khosravinik (2009), sobre refugiados e imigrantes, e por Winkler (2011), sobre a representação dos atores em códigos de ética.

Para Fairclough (2003), a análise da interdiscursividade de um texto é a análise do conjunto de gêneros, discursos e estilos, por meio dos quais os sujeitos se apoiam em suas articulações nos textos. Com isso, a interdiscursividade é uma forma de "constituição heterogênea de textos" (Fairclough, 2001, p. 114). De outra forma, representa "um tipo de discurso [que] é constituído por meio de uma combinação de elementos de ordens de discurso" (Fairclough, 2001, p. 152). Portanto, interdiscursividade se refere também ao amálgama de gêneros discursivos, discursos e estilos (Fairclough, 2003) que pode ser "potencialmente criativo e inovador" (Fairclough, 2003, p. 216).

Quanto ao significado das palavras, Fairclough (2003) afirma que ele faz parte de disputas dentro de outras disputas hegemônicas. Isso porque "as palavras têm tipicamente vários significados, e estes são 'lexicalizados' tipicamente de várias maneiras” (Fairclough, 2001, p. 230). Portanto, a lexicalização de significados envolve "lutas entre atribuições conflitantes de significados - e a variação semântica é vista como um fator de conflito ideológico, pois os significados podem ser política e ideologicamente investidos" (Resende \& Ramalho, 2006, p. 75), constituindo disputas pelo "modelo hegemônico de significado de palavras" (Fairclough, 2001, p. 235). De outra forma, para Fairclough (2001, p. 230): "os significados das palavras e a lexicalização de significados" são socialmente contestadas em "processos sociais e culturais mais amplos". Nesse caso, é possível compreender que as significações da palavra corrupção podem se tornar elementos de disputa discursiva.

\section{Coleta, organização e validação do corpus de análise}

Como corpus de análise foram delimitados, consoante com o debate teórico, textos coletados no Twitter. Para a busca e a seleção, foi utilizada a ferramenta de busca avançada, oferecida pela própria rede social. Primeiramente delimitamos duas revistas de circulação nacional cujos editoriais são comumente contrastantes em termos político-partidários: Revista Veja e Revista CartaCapital. A primeira foi fundada em 1968 e hoje possui suas publicações norteadas por uma posição de direita no espectro político-partidário nacional. Por sua vez, a CartaCapital foi fundada em 1994 e assume uma postura marcada pela esquerda neste aspecto. Ambas são aqui entendidas como mass media em relação ao Twitter. 
Para Gupta (1995), jornais e revistas representam o principal mecanismo de circulação de discursos sobre corrupção na opinião pública. Dada essa relevância, foram coletados discursos publicados em forma de tweets das contas das revistas e das interações entre seus leitores/usuários na rede, por meio das mentions. O tweet é uma mensagem curta (com limite máximo de 140 caracteres) publicada em um espaço denominado timeline, que será visualizado por outros usuários que acompanham/seguem a conta do produtor do texto. Por sua vez, a mention refere-se a um texto produzido como resposta a um determinado tweet, fazendo referência direta ao emissor deste.

Nesse sentido, os tweets e mentions coletados estavam relacionados a textos envolvendo casos de corrupção e respostas dos usuários direcionadas às revistas ou entre si. A partir da análise de outros artigos que utilizam como corpus textos produzidos por usuários da rede Twitter (Lindgren \& Lundström, 2011; Page, 2012; Siapera, Hunt, \& Lynch, 2015), nos resultados deste artigo reproduzimos o conteúdo de tweets na íntegra, sem a correção ortográfica ou gramatical do texto.

A escolha dos casos de corrupção tomou como referência o relatório apresentado pelo Ministério Público Federal (MPF), no qual eram listados os 100 principais casos de combate à corrupção do ano de 2015 (MPF, 2015). Dessa forma, foram escolhidos os casos Operação Zelotes e Operação Lava-Jato, considerando a abrangência e a repercussão nacional desses escândalos na própria mass media e no Twitter. A coleta de dados foi sumarizada conforme a Tabela 1:

Tabela 1

Estratégia de Coleta de Dados no Twitter

\begin{tabular}{lllllll}
\hline Caso & CartaCapital & Tweets & Mentions & Busca & Tweets & Mentions \\
\cline { 2 - 7 } & Busca & 26 & 152 & Zelotes+@VEJA & 32 & 108 \\
\hline Zelotes & Zelotes+@Cartacapital & 29 & 215 & Lava-Jato+@VEJA & 45 & 325 \\
Lava-Jato & Lava-Jato+@Cartacapital & 29 & &
\end{tabular}

Nota. Fonte: Elaborada pelos autores.

Além disso, ainda que representem efeitos das disputas discursivas, procuramos verificar cada uma das contas dos tweets selecionados e incorporados neste artigo, tendo como objetivo confirmar se eram ou não (re)produzidos por socialbots. Para tanto, utilizamos o algoritmo Bot or Not? (Indiana University Bloomington, 2016). Este algoritmo foi desenvolvido por pesquisadores da Indiana University e realiza uma série de testes quanto ao comportamento e conteúdo dos tweets das contas que se pretende analisar (Haustein et al., 2016; Lokot \& Diakopoulos, 2015; Siapera et al., 2015).

O procedimento de validação dos dados se destina a conferir transparência nos procedimentos metodológicos e validade aos resultados encontrados. Dessa forma, trabalhamos com dados autênticos em dois sentidos: (a) verificamos se se tratavam de dados que não eram reproduzidos por socialbots; e (b) são autênticos porque não foram produzidos para fazer parte da pesquisa, mas são textos reais, produzidos e reproduzidos nas ações diárias dos participantes do Twitter. Neste sentido, Mautner (2005) e Sifianou (2015) ressaltam a importância da internet para a composição de um corpus de análise autêntico e atual.

Finalmente, foram analisados inicialmente 932 textos, dentre tweets publicados pelas revistas em questão e mentions publicadas pelos leitores/usuários entre agosto de 2014 e fevereiro de 2016. Como estratégia de análise e apresentação dos resultados, foram consideradas três instâncias de disputas discursivas no Twitter: (a) disputas entre os media (Veja e CartaCapital); (b) disputas entre usuários e media; e (c) disputas entre os próprios leitores/usuários. Antes, devido à importância do contexto para a análise de discurso crítica, apresentamos discussões sobre a visibilidade da corrupção recentemente no Brasil. 


\section{O Contexto do Debate sobre Corrupção no Brasil}

$\mathrm{Na}$ análise de discurso crítica de Fairclough (2001, 2003), o contexto é elemento fundamental do processo de análise/interpretação, já que não é simplesmente um pano de fundo passivo, mas interage dialeticamente com os textos. Portanto, é "um construto analítico que emerge no interior de questões de pesquisa específicas e procura definir a articulação específica dos momentos em que é relevante" (Chouliaraki \& Fairclough, 2010, p. 1215). Do contexto fazem parte as condições de produção, distribuição e consumo dos discursos e outras práticas sociais (Fairclough, 2001). Por isso, este tópico é fundamental para apresentar o contexto envolvendo o tema da corrupção no Brasil.

Azevedo (2006) entende que no Brasil a corrupção é um tema recorrente em conversas cotidianas, nas redes sociais e na mass media, onde são publicizados elementos importantes para formação da opinião pública sobre o fenômeno. Em termos de opinião pública, Avritzer e Filgueiras (2011, p. 7) demarcam que "a corrupção tornou-se um dos principais problemas para a gestão pública e para a democracia". Em janeiro de 2016, uma pesquisa da Confederação Nacional da Indústria mostrou que a corrupção é a maior preocupação de seis em cada dez brasileiros (Confederação Nacional da Indústria, 2016), sendo pela primeira vez destacada como o principal problema do país, a frente das drogas e da violência. Além disso, o documento da organização Transparency International posiciona o Brasil na $76^{\circ}$ colocação no ranking sobre a percepção de corrupção no mundo (Transparency International, 2016).

Atualmente no Brasil, considerando o contexto anteriormente referenciado, são produzidos e reproduzidos diferentes discursos relacionados à corrupção e ao cenário político-partidário nacional. Esse cenário foi construído desde a eleição presidencial realizada no ano de 2014, em que Aécio Neves (candidato do PSDB - Partido da Social Democracia Brasileira) e Dilma Rousseff (candidata do PT Partido dos Trabalhadores) participaram de uma disputa acirrada. Após o processo que resultou na reeleição de Dilma Rousseff, houve diversas manifestações pelo país em defesa e em oposição ao Governo.

É importante destacar que, no ano de 2016, também ocorreram diversas manifestações no país com bandeiras polarizadas a favor do processo de impeachment da Presidente Dilma Rousseff (utilizando as hashtags \#ForaDilma; \#ForaPT; entre outras) e contra o processo (pelas hashtags \#NãoVaiTerGolpe; \#AFavorDaDemocracia; entre outras). Nesta direção, por meio de análise dos veículos de mídia, M. M. Ribeiro, Chalon, Almeida e Orlellado (2016) destacam que as manifestações nas redes sociais geraram efeitos de polarização em que um ator não consegue se comunicar com os dois polos em disputa.

Por fim, convém destacar o contexto das operações a que se referem os discursos de corrupção analisados nesta pesquisa. A Operação Lava-Jato, assim denominada pela Polícia Federal, refere-se a uma operação coordenada pelo Ministério Público Federal (MPF), com apoio da Polícia Federal, deflagrada em março de 2014. Segundo o Ministério Público Federal (2015), a operação investiga casos de negociação de propinas, lavagem e distribuição de dinheiro a políticos a partir de recursos públicos, sendo marcada por uma forte repercussão na mídia.

Por sua vez, a Operação Zelotes trata de outra investigação conduzida pela Polícia Federal, deflagrada em março de 2015 (embora as investigações tenham se iniciado em 2013) e que investiga casos de corrupção no Conselho de Administração de Recursos Fiscais (Carf). A operação envolve grandes empresas privadas do país, servidores públicos e figuras políticas que atuavam manipulando o trâmite de processos e o resultado de julgamentos, o que teria resultado em um desvio de aproximadamente 19 bilhões de reais pelos envolvidos. Ressaltamos que, assim como a Operação LavaJato, a Operação Zelotes tem ganhado grande repercussão na mass media e na opinião pública, incluindo os discursos produzidos nas redes sociais. Todavia, este estudo constatou que a repercussão em termos de escândalo político na mídia foi maior no caso da Operação Lava-Jato. Tal contexto é importante pois é nele que são construídos dialeticamente diversos textos e discursos sobre corrupção. Isso é relevante, antes de tudo, pelo fato de que na ADC o discurso não é algo somente individual (Fairclough, 2001, 2003).

RAC, Rio de Janeiro, v. 21, n. 5, art. 2, pp. 627-647, Setembro/Outubro, 2017, www.anpad.org.br/rac (c) 


\section{Disputas discursivas entre os media}

Considerando os discursos produzidos e veiculados por meio de tweets das revistas analisadas, é possível observar disputas de representações da corrupção. Nesta primeira dimensão de análise, foram consideradas as disputas (indiretas) entre as duas revistas, Veja e CartaCapital, aqui tratadas genericamente como media.

Apesar de não ser a ênfase deste texto, em termos do significado acional, as revistas apresentam uma variedade de gêneros (Fairclough, 2001, 2003), como o informativo e o opinativo, destacando a configuração do Twitter como um gênero híbrido (Souza, Amaral, \& Guimarães, 2011). No entanto, percebemos que o propósito da utilização de determinado gênero é contextual ao caso de corrupção em foco, variando, portanto, entre CartaCapital e Veja - e se relacionando com suas respectivas posições no espectro político-partidário nacional. Adiante, ambas utilizam linguagem formal na maioria dos tweets, denotando ideia de imparcialidade, mas encontramos também casos de uso de ironia como elemento discursivo marcante. Entretanto, os tweets são permeados por seletividades de gêneros, léxicos e temas. Por exemplo, quando a corrupção se refere ao Partido dos Trabalhadores (PT), a revista Veja coloca sempre na chamada elementos como PT, petista ou do governo em evidência. Em contrapartida, a CartaCapital apenas tende a fazer referência a partidos políticos quando a chamada é mais genérica ou quando se refere ao Partido da Social Democracia Brasileira (PSDB), ao passo que, nesses casos, a revista Veja é seletiva no uso do nome desse partido em seus tweets. Quanto ao significado identificacional, as revistas utilizam-se de sinais e intensidade de afirmações para marcar suas posições políticas e hegemônicas. A Veja, por exemplo, nos casos de corrupção ligados à Lava Jato apresenta avaliações e modalidades que denotam certezas e demandas por moralidade da política. Barros (2014), em estudo desenvolvido no Brasil, afirma que veículos da mass media geralmente se apoiam em estratégias de moralização e mitopoiese ao se referirem a narrativas sobre a corrupção.

Além disso, as disputas discursivas pelas representações e legitimidade se tornam presentes principalmente nas ênfases e nos silêncios (ou exclusão, em termos de Fairclough, 2003) conferidos aos casos de corrupção. Ou seja, as revistas selecionadas tratam de forma diferenciada o fenômeno, produzindo discursos distintos. Fairclough $(2001,2003)$ considera essas estratégias ao tratar dos significados das palavras e da relação ideológica e hegemônica acerca disso. Essas discussões corroboram com a visão de Breit (2011), Breit et al. (2015) e Damgaard (2015) no que tange à construção sociodiscursiva de sentidos da corrupção por meio da mídia. Além disso, reforçam os argumentos de Thompson (2011), Breit (2011) e Azevedo (2006) de que a permanência do escândalo na mídia, sua recepção e reprodução dependem, em grande parte, dos meios de comunicação. Dessa forma, por meio do significado representacional (Fairclough, 2001, 2003), destacamos as disputas discursivas marcadas pela seletividade das palavras, das representações e das informações das operações Zelotes e Lava-Jato.

Observamos que, quando a Operação Zelotes foi deflagrada, em março de 2015, as revistas Veja e CartaCapital publicaram um grande volume de notícias. Entretanto, foi possível perceber as diferenças de significações e representações conferidas por cada media. A CartaCapital realça o possível envolvimento de empresas privadas - tais como Globo, Gerdau, RBS, Tim, Ford, entre outras (CartaCapital, 2015a), ao passo que a Veja destaca instituições políticas, como o Conselho Administrativo de Recursos Fiscais (Carf), e, no que se refere às empresas, emprega uma expressão genérica: empresas investigadas (Veja, 2015a, 2015b). A Veja segue, pela análise realizada, a ideia de que o significado da palavra corrupção (Fairclough, 2003) se aplica diretamente em relação ao Setor Público, portanto, configurando sentido ideológico à mesma.

Entre abril e junho de 2015, os tweets da CartaCapital destacaram a indignação seletiva com a corrupção e, ainda, que "o grito contra os corruptos não se importa com os crimes dos sonegadores da Operação Zelotes" (CartaCapital, 2015b). Portanto, a CartaCapital usa como arma discursiva (Barros, 2014) o argumento de que a Operação Zelotes não recebe destaque midiático por envolver grandes empresas. Isso se confirma ao observarmos que a Revista Veja publicou apenas dois tweets entre maio e agosto de 2015, enquanto a CartaCapital publicou 15 no mesmo período. 
Entretanto, em outubro de 2015, o suposto envolvimento ligado à figura do ex-presidente da república Luiz Inácio Lula da Silva (PT) reativou a exposição pela Revista Veja, que aumentou consideravelmente seu número de publicações sobre o caso. Entre outubro de 2015 e janeiro de 2016, a revista tweetou 19 vezes a respeito da Operação Zelotes - o nome Lula aparece em grande parte dos textos. A CartaCapital, ao contrário, reduziu drasticamente o número de tweets publicados após o nome Lula passar a ser relacionado à operação. A revista, que havia publicado 23 tweets entre março e setembro de 2015, publicou apenas três entre outubro de 2015 e janeiro de 2016, deixando de dar destaque ao caso.

Como resultado da primeira disputa discursiva, fica evidente a atuação seletiva (portanto, ideológica) das revistas, corroborando com autores como Fairclough (2001), Breit, (2010) e Thompson, (2011). No que tange à representação dos atores sociais, destacamos a dinâmica constante de inclusão/exclusão em que, a depender dos envolvidos, cada media dá mais ênfase e visibilidade aos casos de corrupção e aos autores envolvidos por meio de supressões nos textos (Fairclough, 2003). Além disso, a dinâmica de nomeação (Fairclough, 2001, 2003) se faz presente com a CartaCapital destacando e nomeando empresas que estariam envolvidas. Por sua vez, a Veja faz silêncio sobre isso e, ao contrário da CartaCapital, nomeia quando envolve o ex-presidente Lula (Veja, 2015c, 2015d, entre outros). Especialmente sobre a nomeação, Resende e Ramalho (2006) nos lembram, a partir de Van Leeuwen, que "a opção pela representação por nomeação ..., de certa forma, significa uma valorização do autor nomeado" (p. 73). Neste caso, cada media procura fixar determinados nomes como relacionados à corrupção e, além disso, a própria palavra corrupção é tratada de forma diferenciada, com significados diferentes em cada media.

Constatamos, por fim, uma disputa pela legitimidade (Hardy \& Phillips, 1999) das próprias operações. A CartaCapital indica em alguns momentos que os procedimentos estão incoerentes e que existe tratamento diferenciado da Operação Zelotes em relação a operação Lava Jato, conforme os Tweets: "Por que a mídia não dá destaque à Operação Zelotes, que flagrou fraudes de mega-empresas?" (CartaCapital, 2015c) e “Onde está o Sergio Moro da Operação Zelotes?” (CartaCapital, 2015d). Dessa forma, por meio do destaque da dinâmica inclusão/exclusão, a revista critica a legitimidade da própria Operação Zelotes.

Em termos da interdiscursividade, ficou constatado também que as revistas Veja e CartaCapital combinam em seus textos ordens de discurso (Fairclough, 2001, 2003) referentes a discursos políticopartidários socialmente compreendidos como de esquerda (CartaCapital) e direita (Veja). Ficou marcado que ambas as revistas são seletivas e, apesar de toda a Operação Zelotes estar centrada em atos de corrupção, os media direcionam sua divulgação no Twitter de acordo com os envolvidos. Isso influencia negativamente a formação de uma opinião pública democrática sobre o tema da corrupção no Brasil, uma vez que os discursos reproduzidos priorizam questões partidárias. Destacamos, por fim, que as lutas apresentadas aqui são, em sua maioria, indiretas. Ou seja, são lutas pela visibilidade/invisibilidade de determinados elementos da corrupção e influenciadas por posições editoriais divergentes.

\section{As disputas discursivas entre usuários e media no Twitter}

A interação/reação dos usuários diante dos tweets é o que tratamos aqui como o segundo nível de disputa discursiva e refere-se aos embates envolvendo os discursos produzidos por usuários/autores e os media. Diferente do nível de disputa analisado anteriormente, neste caso, os usuários demarcam suas posições discursivas e ideológicas interagindo com as revistas. Essa interação ocorre por meio de mentions, retweets e likes (sinalizações visuais de aprovação ao discurso publicado por outros autores).

Observamos que os usuários se posicionam contrários ou favoráveis aos discursos produzidos pelos media, caracterizando uma prática comum em disputas discursivas (Barros, 2014), além de demarcarem as representações da corrupção e as posições dos falantes. Por um lado, os usuários que se posicionam a favor de um determinado tweet atuam de modo a reforçar a legitimidade daquele discurso; por outro, aqueles que se posicionam de forma contrária, o fazem por meio de estratégias discursivas 
que procuram deslegitimar o discurso da mídia. Considerando a Operação Lava-Jato, a revista CartaCapital publicou: "O juiz da Lava Jato conduz cruzada à corrupção e ao descrédito da política" (CartaCapital, 2015e).

Este tweet reproduz o discurso produzido em uma coluna publicada pela revista, na qual o autor questiona o modo com o qual as investigações da Polícia Federal, na figura central do juiz responsável pelos inquéritos, têm sido tratadas, bem como a própria noção de corrupção e seus efeitos na política. Neste enunciado, o juiz Sérgio Moro é qualificado como polêmico e parcial. Após o tweet ser publicado, usuários começaram a se posicionar com relação ao discurso da revista, a maioria destes de forma contrária, por meio de estratégias de autorização e avaliação moral, conforme Fairclough (2003) a partir de van Leeuwen, destacando que a ação da Polícia Federal é justificável e necessária para a transformação do Brasil em um país decente e justo. Além disso, nessa disputa, percebe-se a impessoalização (Fairclough, 2003; Thompson, 2011) da corrupção e sua atribuição a um partido, o Partido dos Trabalhadores, como segue: "Chororo de um torcedor do PT. Tem de investigar tudo. Problema do PT se optou pelo caminho errado" (Luiz Claudio, 2015).

Por sua vez, outro usuário se posiciona a favor do texto reproduzido pela revista, apontando que a investigação da corrupção é seletiva e que ignora outros partidos: "corrupção, seletiva... Ignora o que fazem demo-tucanos, Cunha e quetais" (Gobbis, 2015). Assim, fica demarcado que os usuários reagem de formas diversas às postagens, produzindo e reproduzindo discursos que visam legitimar ou deslegitimar os tweets dos media.

Como exemplo, destacamos o seguinte tweet relacionado à Lava-Jato: "\#VejaPersonalidade2015 \#Retrô Sergio Moro: "Na Lava Jato, me deparei com corrupção sistêmica"” (Veja, 2015e). O texto representa Sérgio Moro como uma das personalidades do ano de 2015. A revista usa a estratégia discursiva das hashtags \#VejaPersonalidade2015 e \#Retrô para ampliar o alcance do discurso, uma vez que tais expressões são destacadas visualmente no texto e possibilitam que outros leitores se interconectem com as mesmas por meio do agrupamento de tweets que utilizaram tal hashtag. Percebemos que os tweets revelam posições opostas das revistas: enquanto uma critica o Juiz Sérgio Moro, chamando-o de polêmico e parcial, a outra o chama de personalidade do ano. Notamos que vários usuários concordaram com o texto reproduzido, legitimando a representação da corrupção como um problema de natureza sistêmica: "Parabéns Moro. Ta faltando suspender os partidos politicos que receberam propina. No mínimo reduzir tempo no horário politico!" (Cavichiolo, 2015) ou "sistêmica e que está colocando o Brasil em estado de septicemia" (Altoé, 2015).

As disputas discursivas também estão presentes nos discursos relacionados à Operação Zelotes. A revista CartaCapital publicou um gênero opinativo (Fairclough, 2003) referente à denominada seletividade dos discursos nos protestos populares realizados em todo o país, em abril de 2014. Nessas manifestações, o combate à corrupção era um dos principais temas: "O grito contra os corruptos não se importa com os crimes dos sonegadores da Operação Zelotes: http://bit.ly/1GZ7Cse" (CartaCapital, 2015b).

Após a publicação, vários usuários se posicionaram de forma contrária ao discurso da revista. Esses sujeitos utilizaram de estratégias de racionalização (Fairclough, 2003) ao argumentar que apesar da existência de outros casos de corrupção, a opinião pública deve focar em casos particulares, neste contexto, aqueles relacionados ao PT: "este grito do povo brasileiro não compactua com nenhum tipo de corrupção. Somos apartidários. agora o foco é \#ForaPT" (Murce, 2015). Além disso, outra usuária procura criticar o discurso da revista comparando-a com a própria revista Veja: "A CartaCapital é uma Veja Mal resolvida: Não investiga, não aprofunda (inferior à Veja) e ainda tem direção clara (igual)" (Medeiros, 2015). Contudo, também é possível identificar discursos que procuram legitimar o tweet da CartaCapital referindo-se aos manifestantes como indivíduos organizados e mobilizados por grupos tidos como corruptos: "Eles nem sabem q os corruptos são os q chamaram pra essa manifestação!" (Dandara dos Palmares, 2015).

Dessa forma, mais uma vez foram destacadas representações sobre a corrupção com forte apelo político-partidário. Esses resultados mostram a ampla presença de ideologias de partido nos discursos 
sobre corrupção, além de ficarem visíveis também as diferentes posições das revistas Veja e CartaCapital e a seletividade dos discursos. Os discursos referentes aos debates partidários são elementos interdiscursivos (Fairclough, 2003) presentes nos textos.

É importante destacar que alguns usuários percebem às posições partidárias, ideológicas e à seletividade das revistas, e criticam as mesmas a partir de outras posições discursivas. Esta questão é importante do ponto de vista de práticas de contestação dos discursos hegemônicos: "Não, o que falta é ser imparcial, denunciar todos a inclusive e o PT, e isso não acontece na @cartacapital" (NatusDDT, 2016) - referindo-se à CartaCapital - e "ei, e o mensalão tucano? Tá parado desde quando? Merece matéria também? Bora trabalhar nisso?" (Costa, 2014) - em resposta a tweet da Revista Veja. Este elemento pode ser relacionado à questão da reflexividade dos atores (Chouliaraki, \& Fairclough, 2010) diante dos textos reproduzidos e que, diferente de algumas Teorias do Discurso, a ADC concebe a agência dos sujeitos sociais diante das ordens discursivas e da hegemonia presente.

Portanto, na análise das disputas entre usuários e media no Twitter, ficou evidente também que um mesmo episódio pode produzir vários discursos distintos (Fairclough, 2003), além das várias gramáticas que são publicizadas no que tange ao entendimento da corrupção (Damgaard, 2015). Adiante, Fairclough (2003) discute que o significado das palavras se constrói dentro de disputas hegemônicas e, nesse sentido, nos tweets, a lexicalização da corrupção envolve lutas por atribuições de significados e representações - esse significado depende de "um modo de hegemonia e um foco de luta" (Fairclough, 2001, p. 288). Nisso, a pesquisa revela que o próprio significado da corrupção se apresenta permeado por disputas sociais, ideológicas e político-partidárias em curso no país - revelando também elementos daquilo que Fairclough $(2001,2003)$ entende como dialética entre discurso e sociedade.

\section{As disputas discursivas entre usuários no Twitter}

Na terceira instância de análise deste estudo, investigamos as disputas discursivas entre os próprios usuários do Twitter. Estas disputas são relevantes para a demarcação de posições que legitimam, criticam ou resistem a discursos produzidos na rede social, bem como constroem significados sobre a corrupção mobilizados pela opinião pública e pela mass media. Como já destacado, as disputas ocorreram por meio de recursos da rede social tais como mentions, retweets e likes. Nesse caso, procuramos analisar as interações diretas entre usuários após tweets publicados pelos media.

No que se refere ao sentido da corrupção, a revista CartaCapital publicou "A percepção de que a corrupção é um problema exclusivo do setor público foi abalada com a Operação Lava Jato" (CartaCapital, 2014). Após esse tweet, dois usuários se engajaram em um diálogo no qual duas representações da corrupção são apresentadas, uma delas pessimista, relacionando a impunidade da corrupção ao poder econômico, e outra que entende que a pressão popular pode ser um meio para uma punição exemplar aos envolvidos: "foi? ainda não vi um punido" (Kaiowá, 2014), cuja réplica foi "temos que pressionar p/q todos culpados, do setor público ou privado, sejam punidos exemplarmente!" (Nilo, 2014), seguida pela tréplica "adoraria pensar que a pressão é suficiente, mas o poder econômico está com eles” (Kaiowá, 2014).

No entanto, como nas análises anteriores, percebemos que as disputas discursivas entre usuários desenvolvem-se comumente por meio do confronto de posições partidárias (articuladas interdiscursivamente) quanto à seletividade, adição ou exclusão de determinados atores ou eventos no discurso produzido pelos media. A revista Veja publicou: "Querem parar a operação Lava Jato. E não é por falta de água. Saiba mais nesta edição de @VEJA" (Veja, 2014). Após isso, duas usuárias se engajaram em uma disputa:

"ei, e o mensalão tucano? Tá parado desde quando? Merece matéria também? Bora trabalhar nisso?" (Costa, 2014);

"vai ler a CartaCapital ou 247 lá e especialidade na indústria da calúnia do PT" (coxinha do textão, 2014); 
· "é verdade, aqui só tem as calúnias do PSDB, o sistema é forte" (Costa, 2014);

- "leia a UOl também petralhinha, mensalão mineiro e do coordenador de campanha da Dilma, nisso o PT também tá" (coxinha do textão, 2014);

· “Aconselho a ler a história do Brasil, melhoras gata" (Costa, 2014);

· “aconselho a parar de falar merda, gatona!!!" (coxinha do textão, 2014);

"não dissemine o ódio. Mais amor no coração. Melhoras no vocabulário" (Costa, 2014);

"não me meça pela sua régua quem estimulou ódio foram vocês petralhas, agora aguentem" (coxinha do textão, 2014).

Na disputa acima (ocorrida após um Tweet da Revista Veja), a representação da corrupção novamente assume o caráter partidário, sendo demarcado pelo uso da ironia que, por sua vez, desencadeia no acirramento das posições que deixam de tratar da corrupção e passam a focar em trocas ofensivas de tweets. Além disso, uma das usuárias justifica o ódio expresso no discurso como uma reação estimulada pelas próprias ações do outro grupo, os petralhas (em referência ao PT). Nessa disputa, observamos a presença da representação da corrupção como um fenômeno ligado diretamente a um partido político. Percebemos a interdiscursividade existente nesse tweet ao considerarmos a existência de um discurso hegemônico no nível societal que se refere à corrupção do país como culpa do PT (Tatagiba, Teixeira, \& Trindade, 2015), frequentemente reproduzido pela revista Veja.

De modo geral, na maioria dos casos percebemos que as disputas discursivas entre os usuários do Twitter também refletem a polarização política reproduzida pelas revistas analisadas (outro traço de interdiscursividade com discursos no nível societal). As análises revelaram elementos marcados pelos seguintes modos de operacionalização de construções simbólicas (ideológicas): universalização (todos de um partido são corruptos), simbolização da unidade (todos são corruptos no partido - PT), expurgo do outro (um partido se torna inimigo da moralidade nacional), naturalização (a corrupção aparece como natural e cultural em vários discursos) e, principalmente, normalização/passivação (com concentração da atenção em determinados temas e atores e apagamento de outros).

Sobre as representações (significado representacional), é importante destacar que da mesma forma que um texto não representa um discurso - daí a importância de destacar elementos como interdiscursos, significados das palavras, ordens do discurso, relações entre textos, práticas discursivas e práticas sociais (Fairclough, 2001) - cada representação individual não representa um discurso. Neste sentido, Fairclough (2003) coloca: "in talking about discourses as different ways of representing, we are implying a degree of repetition, commonality in the sense that they are shared by groups of people, and stability over time" (p. 124). Por isso, em geral, as representações (mesmo que em um texto existam várias), os significados, interdiscursos e outros elementos emergem dos vários tweets (textos) analisados durante todo o período, e não apenas de um em particular.

Por fim, a Tabela 2 apresenta um resumo com os principais resultados do artigo, destacando os elementos centrais para os tópicos representação de atores, interdiscursividade, significados das palavras e disputas discursivas. 
Tabela 2

\section{Quadro-Resumo com os Principais Resultados do Artigo}

\begin{tabular}{ll}
\hline Tópicos & Principais resultados \\
\hline $\begin{array}{l}\text { Representação dos } \\
\text { atores }\end{array}$ & $\begin{array}{l}\text { As representações e os sentidos em relação à corrupção atribuídos pelos atores no Twitter } \\
\text { são marcadas por naturalizações, seletividade dos media (em seus textos divulgados na } \\
\text { rede), momentos de inclusão/exclusão e nomeação. }\end{array}$ \\
\hline Interdiscursividade & $\begin{array}{l}\text { Os discursos sobre a corrupção publicados pelos sujeitos na rede social apresentam } \\
\text { interdiscurso com outros tipos de representações que demarcam a conjuntura política e }\end{array}$ \\
& $\begin{array}{l}\text { ideológica do país. Dentre essas representaçôes, destacamos traços da polarização } \\
\text { político-partidária, bem como o discurso da corrupção como prática inerente ao setor } \\
\text { público e o discurso da moralização da política. }\end{array}$ \\
\hline Significados das & $\begin{array}{l}\text { Identificamos que o significado da corrupção atribuído pelos sujeitos é construído } \\
\text { palavras }\end{array}$ \\
$\begin{array}{l}\text { interdiscursivamente e é permeado por disputas sociais, ideológicas e político-partidárias } \\
\text { em curso no país. Assim, esse fenômeno assume sentidos diferentes a depender dos } \\
\text { falantes. }\end{array}$ \\
\hline $\begin{array}{l}\text { As disputas discursivas em torno dos sentidos da corrupção são materializadas entre os } \\
\text { discursivas }\end{array}$ & $\begin{array}{l}\text { veículos de media, entre os media e os leitores/usuários e entre os próprios usuários da } \\
\text { rede. Essas disputas são performatizadas, sobretudo, por meio de estratégias de } \\
\text { racionalização e avaliação moral. Esta última estratégia foi especialmente marcante em } \\
\text { discursos que remetem a uma limpeza moral da corrupção no Brasil. Esse discurso, por } \\
\text { sua vez, interage interdiscursivamente com sentidos que nomeiam a corrupção como uma } \\
\text { prática característica de grupos específicos. }\end{array}$ \\
\hline
\end{tabular}

Nota. Fonte: Elaborado pelos autores.

A seguir, apresentamos as principais discussões do artigo, suas limitações e agenda de pesquisas futuras que tendam a contribuir para os Estudos Organizacionais.

\section{Considerações Finais}

O Twitter configura-se atualmente no Brasil como um espaço de disputas sobre os significados da corrupção marcadas por dinâmicas de naturalizações, seletividade dos media (em seus textos divulgados no Twitter), expurgo do outro, inclusão/exclusão, nomeação e estratégias de racionalização e avaliação moral. Neste contexto, destaca-se a estratégia discursiva de avaliação moral, observada em discursos que chamam para uma limpeza moral da corrupção no país, e também para o caráter simbólicoideológico do discurso que relaciona corrupção e o Partido dos Trabalhadores.

Encontramos elementos que mostram que a construção da corrupção é também resultado de processos de produção de sentidos inseridos em campos sociais e políticos - com papel marcante da mídia, o que Breit (2011) e Damgaard (2015) já haviam observado. Neste sentido, constatamos que a corrupção não é apenas uma objetivação presente nesses processos de produção de sentidos, mas um fenômeno criado e amplificado por esses processos - especialmente pelo fenômeno da midiatização e da ênfase na construção de escândalos. Em decorrência disso, indicamos que a construção social da corrupção no Brasil se faz em meio a divergências de argumentos, opiniões e representações que proporcionam e mobilizam disputas discursivas. Essas considerações também desnaturalizam a suposta imparcialidade das revistas e, dessa forma, corroborando com Damgaard (2015), as análises indicam que os meios de comunicação realizam papéis diferentes em casos de corrupção. Portanto, as revistas (e a mídia em geral) podem escolher lados nas disputas sócio-políticas.

As análises revelaram que os textos sobre a corrupção se intensificaram recentemente, não somente mobilizados pelos casos de corrupção que ganharam grande exposição midiática, mas 
principalmente em decorrência do clima político-partidário nacional. Percebemos também que os discursos disponibilizados pelas mídias e pelos usuários/autores podem dialeticamente constituir momentos de disputas hegemônicas. Além disso, podemos considerar que os discursos sobre corrupção se articulam interdiscursivamente com discursos ideológico-partidários. Os resultados indicam ainda que as redes sociais, no que tange a corrupção, tornaram-se locais de disputas discursivas em prol da legitimidade e dos sentidos atribuídos à corrupção, intensamente polarizados politicamente e praticamente sem abertura para visões que superem as questões partidárias. Corroborando com Damgaard (2015), a corrupção é usada como elemento para moldar o discurso público.

Essas foram as indicações teórico-empíricas desta pesquisa, ainda inédita no que tange à relação entre mass media, redes sociais e corrupção no Brasil sob a ótica dos discursos e seus significados. Cabe destacar como limitação que essa análise está restrita ao Twitter que, apesar de um grande número de participantes, possui limitações, pois o acesso é restrito para quem possui conta na rede social (Souza et al., 2011). Da mesma forma, nem todos os usuários da rede participam ativamente de debates e não foi possível conhecer o perfil dos participantes das disputas discursivas - além de termos demarcado incialmente apenas duas revistas e dois casos de corrupção para fins de operacionalização da pesquisa. Portanto, a partir disto, é possível ampliar a pesquisa, considerando além dos medias nacionais, a recepção internacional dos casos de corrupção no Brasil e outros elementos.

Como agenda de pesquisas futuras indicamos as possibilidades de: (a) analisar comparativamente os potenciais de debate sobre a corrupção em diferentes redes sociais, tais como Facebook ou Instagram; (b) entender se e como o dialogismo (na perspectiva de Bakhtin) nas redes sociais pode proporcionar processos de aprendizagem e mudança de atitude; (c) compreender como ocorreu a luta discursiva pela legitimidade do processo de impeachment, realizado em 2016, no Brasil e como o tema da corrupção figurou nestas disputas; e (d) aprofundar, à luz das Teorias do Discurso (incluindo a ADC), meios de pesquisas discursivas que considerem o fenômeno dos socialbots. Essas questões são importantes tendo em vista contribuições para o campo dos Estudos Organizacionais em estudos sobre corrupção.

Finalmente, a perspectiva da análise de discurso crítica de Fairclough $(2001,2003)$ indica que a forma como os usuários discutem no Twitter é, na verdade, produto de lutas hegemônicas, de orientações sócio-ideológicas e de estratégias em disputas discursivas, e não somente de uma dimensão psicologizante da participação dos sujeitos nas redes sociais e, por isso, precisam ser analisadas por uma ótica que concebe a dialética entre discurso e sociedade.

\section{Referências}

Abramo, C. W. (2005). Percepções pantanosas: A dificuldade de medir a corrupção. Novos Estudos CEBRAP, (73), 33-37. http://dx.doi.org/10.1590/s0101-33002005000300003

Altoé, L. (2015, dezembro 19). \#VejaPersonalidade2015 \#RetrôSergio Moro: 'Na Lava Jato, me deparei com corrupção sistêmica' [Twitter]. Recuperado de: https://twitter.com/Lucianaltoe/status/678396406370074628

Ausserhofer, J., \& Maireder, A. (2013). National politics on Twitter: structures \& topics of a networked public sphere. Information, Communication \& Society, 16(3), 291-314, http://dx.doi.org/10.1080/1369118X.2012.756050

Avritzer, L. (2016). Os impasses da democracia no Brasil. Rio de Janeiro: Civilização Brasileira.

Avritzer, L., \& Filgueiras, F. (2011). Corrupção e controles democráticos no Brasil [Texto para discussão, $\left.\mathrm{N}^{\circ} 32\right]$. Brasília, DF: CEPAL-IPEA.

Azevedo, F. A. (2006). Mídia e democracia no Brasil: Relações entre o sistema de mídia e o sistema político. Opinião Pública, 12(1), 88-113. http://dx.doi.org/10.1590/S0104-62762006000100004 
Barros, M. (2014). Tools of legitimacy: The case of the Petrobras corporate blog. Organization Studies, 35(8), 1211-1230. http://dx.doi.org/10.1177/0170840614530914

Boshmaf, Y., Muslukhov, I., Beznosov, K., \& Ripeanu, M. (2012). Design and analysis of a social botnet. Computer Networks, 57(2), 556-578. http://dx.doi.org/10.1016/j.comnet.2012.06.006

Breit, E. (2010). On the (re) construction of corruption in the media: A critical discursive approach. Journal of Business Ethics, 92(4), 619-635. http://dx.doi.org 10.1007/s10551-009-0177-y

Breit, E. (2011). Discursive contests of corruption: The case of the Norwegian alcohol monopoly. Culture \& Organization, 17(1), 47-64. http://dx.doi.org/10.1080/14759551.2011.530744

Breit, E., Lennerfors, T. T., \& Olaison, L. (2015). Critiquing corruption: A turn to theory. ephemera: theory \& politics in organization, 15(2), 319-336.

CartaCapital. (2014, dezembro 28). A percepção de que a corrupção é um problema exclusivo do setor público foi abalada com a Operação Lava Jato [Twitter]. Recuperado de https://twitter.com/cartacapital/status/549188068960657408

CartaCapital. (2015b, abril 13). O grito contra os corruptos não se importa com os crimes dos sonegadores da Operação Zelotes [Twitter]. Recuperado de https://twitter.com/cartacapital/status/587457706941886464

CartaCapital. (2015e, agosto 2). O juiz da Lava Jato conduz cruzada à corrupção e ao descrédito da política. Por Mauricio Dias [Twitter]. Recuperado de https://twitter.com/cartacapital/status/627984767909294080

CartaCapital. (2015d, agosto 10). Onde está o Sergio Moro da Operação Zelotes? [Twitter]. Recuperado de https://twitter.com/cartacapital/status/630793235271680000

CartaCapital. (2015a, março 31). Operação Zelotes: Gerdau e RBS, afiliada da Globo, são principais alvos, diz jornal [Twitter]. Recuperado de https://twitter.com/cartacapital/status/583056302680748032

CartaCapital. (2015c, junho 26). Por que a mídia não dá destaque à Operação Zelotes, que flagrou fraudes de mega-empresas? [Twitter]. Recuperado de https://twitter.com/cartacapital/status/614482040210243584

Cavichiolo, S. (2015, dezembro 19). Moro: 'Na Lava Jato, me deparei com corrupção sistêmica' [Twitter]. Recuperado de https://twitter.com/engsergiofranco/status/678377581029302272

Chiluwa, I. (2012). Social media networks and the discourse of resistance: A sociolinguistic CDA of Biafra online discourses. Discourse \& Society, 23(3), 217-244. http://dx.doi.org/10.1177/0957926511433478

Chiluwa, I., \& Ifukor, P. (2015). 'War against our Children': Stance and evaluation in \#BringBackOurGirls campaign discourse on Twitter and Facebook. Discourse \& Society, 26(3), 267-296. http://dx.doi.org/10.1177/0957926514564735

Chouliaraki, L., \& Fairclough, N. (2010). Critical discourse analysis in organizational studies: Towards an integrationist methodology. Journal of Management Studies, 47(6), 1213-1218. http://dx.doi.org/10.1111/j.1467-6486.2009.00883.x

Cobb, M. D., \& Taylor, A. J. (2015). An absence of malice: The limited utility of campaigning against party corruption. American Politics Research, 43(6), 923-951. http://dx.doi.org/10.1177/1532673X15570470 
Confederação Nacional da Indústria. (2016, janeiro). Problemas e prioridades para 2016: Corrupção é o principal problema do país. Retratos da Sociedade Brasileira, (28), Ano 5, 1-6.

Costa, A. K. (2014, outubro 31). Querem parar a operação Lava Jato. E não é por falta de água [Twitter]. Recuperado de https://twitter.com/anakatiacosta/status/528333682189545473

coxinha do textão. (2014, outubro 31). Querem parar a operação Lava Jato. E não é por falta de água. [Twitter]. Recuperado de https://twitter.com/LelexDutra/status/528334160306659328

Damgaard, M. (2015). Corruption: multiple margins \& mediatized transgression. ephemera: theory \& politics in organization, 15(2), 411-434.

Dandara dos Palmares. (2015, abril 13). O grito contra os corruptos não se importa com os crimes dos sonegadores da Operação Zelotes [Twitter]. Recuperado de: https://twitter.com/tririos/status/587458444493508608

Fairclough, N. (1985). Critical and descriptive goals in discourse analysis. Journal of Pragmatics, 9(6), 739-763. https://dx.doi.org/10.1016/0378-2166(85)90002-5

Fairclough, N. (2001). Discurso e mudança social. Brasília: Editora UnB.

Fairclough, N. (2003). Analysing discourse: Textual analysis for social research. London: Psychology Press.

Fairclough, N. (2005). Peripheral vision discourse analysis in organization studies: The case for critical realism. Organization Studies, 26(6), 915-939. http://dx.doi.org/10.1177/0170840605054610

Fairclough, N. (2012). Análise crítica do discurso como método em pesquisa social científica. Linha d'Água, 25(2), 307-329. http://dx.doi.org/10.11606/issn.2236-4242.v25i2p307-329

Filgueiras, F. (2009). A tolerância à corrupção no Brasil: Uma antinomia entre normas morais e prática social. Opinião Pública, 15(2), 386-421. http://dx.doi.org/10.1590/s0104-62762009000200005

Gleiss, M. S. (2015). Speaking up for the suffering (br)other: weibo activism, discursive struggles, \& minimal politics in China. Media, Culture \& Society, 37(4), 513-529. http://dx.doi.org/10.1177/0163443714566897

Gobbis, A. (2015, agosto 2). O juiz da Lava Jato conduz cruzada à corrupção e ao descrédito da política [Twitter]. Recuperado de https://twitter.com/xandaodalapa/status/628037355337838592

Gupta, A. (1995). Blurred boundaries: The discourse of corruption, the culture of politics and the $\begin{array}{llll}\text { imagined state. } & \text { American }\end{array}$ http://dx.doi.org/10.1525/ae.1995.22.2.02a00090

Hardy, C., \& Phillips, N. (1999). No joking matter: discursive struggle in the Canadian refugee system. Organization Studies, 20(1), 1-24. http://dx.doi.org/10.1177/0170840699201001

Harley, B., \& Hardy, C. (2004). Firing blanks? An analysis of discursive struggle in HRM. Journal of Management Studies, 41(3), 377-400. http://dx.doi.org/10.1111/j.1467-6486.2004.00437.x

Haustein, S., Bowman, T. D., Holmberg, K., Tsou, A., Sugimoto, C. R., \& Larivière, V. (2016). Tweets as impact indicators: Examining the implications of automated "bot" accounts on Twitter. Journal of the Association for Information Science and Technology, 67(1), 232-238. http://dx.doi.org/10.1002/asi.23456

Indiana University Bloomington. (2016, December 20). Bot or Not? A Truthy project. Retrieved from http://truthy.indiana.edu/botornot/ 
Jackson, L., \& Valentine, G. (2014). Emotion \& politics in a mediated public sphere: Questioning democracy, responsibility \& ethics in a computer mediated world. Geoforum, 52, 193-202. http://dx.doi.org/10.1016/j.geoforum.2014.01.008

Kaiowá. (2014, dezembro 28). A percepção de que a corrupção é um problema exclusivo do setor público foi abalada com a Operação Lava Jato [Twitter]. Recuperado de https://twitter.com/WWWilton/status/549190326548975617

Khosravinik, M. (2009). The representation of refugees, asylum seekers and immigrants in British newspapers during the Balkan conflict (1999) and the British general election (2005). Discourse \& Society, 20(4), 477-498. http://dx.doi.org/10.1177/0957926509104024

Lindgren, S., \& Lundström, R. (2011). Pirate culture and hacktivist mobilization: The cultural and social protocols of \#WikiLeaks on Twitter. New Media \& Society, 13(06), 999-1018. http://dx.doi.org/10.1177/1461444811414833

Lokot, T., \& Diakopoulos, N. (2015). News bots. Digital Journalism, 4(6), 682-699. http://dx.doi.org/10.1080/21670811.2015.1081822

Luiz Claudio. (2015, agosto 2). O juiz da Lava Jato conduz cruzada à corrupção e ao descrédito da política [Twitter]. Recuperado de https://twitter.com/luclsluiz/status/627987905688899584

Maireder, A., \& Schlögl, S. (2014). 24 hours of an \#outcry: the networked publics of a socio-political debate. European Journal of Communication, 29(6), 687-702. http://dx.doi.org/10.1177/0267323114545710

Mautner, G. (2005). Time to get wired: Using web-based corpora in critical discourse analysis. Discourse \& Society, 16(6), 809-828. http://dx.doi.org/10.1177/ 0957926505056661

Medeiros, V. (2015, abril 13). O grito contra os corruptos não se importa com os crimes dos sonegadores da Operação Zelotes [Twitter]. Recuperado de https://twitter.com/veramedeiros9/status/587534061884801025

Ministério Público Federal. (2015). 100 casos de combate à corrupção do ano de 2015. Recuperado em 28 de fevereiro, 2016 de https://slate.adobe.com/cp/DgF4n/

Murce, A. (2015, abril 13). O grito contra os corruptos não se importa com os crimes dos sonegadores da Operação Zelotes [Twitter]. https://twitter.com/abiliomurce/status/587474847959232512

NatusDDT. (2016, janeiro 26). Operação Lava Jato: Justiça aceita denúncia sobre corrupção na Petrobras da "era FHC" [Twitter]. Recuperado de https://twitter.com/NATUSDDT/status/691899564706680833

Nilo, A. (2014, dezembro 28). A percepção de que a corrupção é um problema exclusivo do setor público foi abalada com a Operação Lava Jato [Twitter]. Recuperado de https://twitter.com/WWWilton/status/549190326548975617

Page, R. (2012). The linguistics of self-branding and micro-celebrity in Twitter: The role of hashtags. Discourse \& Communication, 6(2), 181-201. http://dx.doi.org/10.1177/1750481312437441

Resende, V. D. M., \& Ramalho, V. (2006). Análise de discurso crítica. São Paulo: Contexto.

Ribeiro, M. M., Chalon, A., Almeida, L. H., \& Orlellado, P. (2016, março 24). Perfil digital dos manifestantes de 13 e 18 de março. Recuperado de https://gpopai.usp.br/polarizacao.pdf

Ribeiro, P. F., Vizoná, A., \& Cassotta, P. L. (2016). Brasil: Un país en compás de espera. Revista de ciencia política (Santiago), 36(1), 51-74. http://dx.doi.org/10.4067/S0718-090X2016000100003 
Rose-Ackerman, S. (2001). Trust, honesty \& corruption: Reflection on the state-building process. European Journal of Sociology, 42(3), 526-570. http://dx.doi.org/10.1017/S0003975601001084

Siapera, S, Hunt, G., \& Lynn, T. (2015). \#GazaUnderAttack: Twitter, Palestine and diffused war. $\begin{array}{llll}\text { Information, } \quad \text { Communication \& } \quad \text { Society, } & \text { 18(11), }\end{array}$ http://dx.doi.org/10.1080/1369118X.2015.1070188

Sifianou, M. (2015). Conceptualizing politeness in Greek: Evidence from Twitter corpora. Journal of Pragmatics, 86, 25-30. http://dx.doi.org/10.1016/j.pragma.2015.05.019

Souza, C. C., Amaral, M. S., \& Guimarães, S. A. H. (2011). A multifuncionalidade do Twitter sob a perspectiva da análise crítica do discurso: Uma análise de tweets sobre a profissão-perigo professor. Linguagens e Diálogos, 2(1), 1-30.

Strömbäck, J., \& Esser, F. (2014). Introduction: making sense of the mediatization of politics. Journalism Studies, 15(3), 243-255. http://dx.doi.org/10.1080/1461670X.2014.897412

Tatagiba, L., Teixeira, A. C. C., \& Trindade, T. A. (2015). Protestos à direita no Brasil (2007-2015). In S. V. Cruz, A. Kaysel, \& G. Codas (Orgs.), Direta volver! O retorno da direita e o ciclo político brasileiro (pp. 197-213). São Paulo: Fundação Perseu Abramo.

Thompson, J. (2011). Ideologia e cultura moderna: Teoria social crítica na era dos meios de comunicação em massa. Petrópolis: Vozes.

Transparency International. (2016). Corruption perception index 2015. Retrieved from https://www.transparency.org/cpi2015\#results-table

Veja. com. (2014, outubro 31). Querem parar a operação Lava Jato. E não é por falta de água [Twitter]. Recuperado de https://twitter.com/VEJA/status/528328159486545922

Veja. com. (2015b, abril 8). Fazenda vai abrir processos contra empresas investigadas na Operação Zelotes [Twitter]. Recuperado de https://twitter.com/VEJA/status/585834493354840064

Veja. com. (2015c, outubro 1). Filho de Lula recebeu dinheiro de escritório investigado na Zelotes [Twitter]. Recuperado de https://twitter.com/VEJA/status/649569459284385793

Veja. com. (2015e, dezembro 19). Moro: 'Na Lava Jato, me deparei com corrupção sistêmica' [Twitter]. Recuperado de https://twitter.com/VEJA/status/678372672921853953

Veja. com. (2015a, abril 1). Operação Zelotes: Nem todos os julgamentos do Carf serão alterados [Twitter]. Recuperado de https://twitter.com/VEJA/status/583439712221851648

Veja. com. (2015d, outubro 8). Sócia de escritório que pagou filho de Lula também é alvo da Operação Zelotes [Twitter]. Recuperado de https://twitter.com/VEJA/status/650132165724925952

Winkler, I. (2011). The representation of social actors in corporate codes of ethics. How code language positions internal actors. Journal of Business Ethics, 101(4), 653-665. http://dx.doi.org/10.1007/s10551-011-0762-8

Woolley, S. C. (2016). Automating power: social bot interference in global politics. First Monday, 21(4). Retrieved from http://firstmonday.org/ojs/index.php/fm/article/view/6161/5300. http://dx.doi.org/10.5210/fm.v21i4.6161 


\section{Dados dos Autores}

André Luiz de Paiva

DAE/UFLA, Caixa Postal 3037, 37200-000, Lavras, MG, Brasil. E-mail: andrepaiva2@ gmail.com

André Spuri Garcia

DAE/UFLA, Caixa Postal 3037, 37200-000, Lavras, MG, Brasil. E-mail: andrespurigarcia@ gmail.com

Valderí de Castro Alcântara

DAE/UFLA, Caixa Postal 3037, 37200-000, Lavras, MG, Brasil. E-mail: valderidecastroalcantara@gmail.com 